\author{
RESEARCH ARTICLE \\ 10.1029/2019JC015709 \\ Key Points: \\ - An array of 247 geophones was \\ deployed on sea ice for 27 days \\ during winter 2019 \\ - Broadband dispersion of several \\ guided wave modes propagating in \\ sea ice were extracted from passive \\ seismic data \\ - Sea ice thickness and elastic \\ properties were estimated from \\ guided wave dispersion
}

Correspondence to:

L. Moreau,

ludovic.moreau@univ-grenoble-alpes.fr

Citation:

Moreau, L., Boué, P., Serripierri, A., Weiss, J., Hollis, D., Pondaven, I., et al. (2020). Sea ice thickness and elastic properties from the analysis of multimodal guided wave propagation measured with a passive seismic array. Journal of Geophysical Research: Oceans, 125, e2019JC015709. https:// doi.org/10.1029/2019JC015709

Received 30 SEP 2019

Accepted 9 MAR 2020

Accepted article online 20 MAR 2020

\section{Sea Ice Thickness and Elastic Properties From the Analysis of Multimodal Guided Wave Propagation Measured With a Passive Seismic Array}

\author{
Ludovic Moreau' $^{1}$ (D), Pierre Boué ${ }^{(i D}$, Agathe Serripierri ${ }^{1}$, Jérôme Weiss ${ }^{1}$ iD, Daniel Hollis ${ }^{1}$, \\ Ildut Pondaven ${ }^{1}$, Benjamin Vial ${ }^{1}$, Stéphane Garambois $^{1}$, Éric Larose $^{1}$, Agnés Helmstetter ${ }^{1}$ (iD), \\ Laurent Stehly $^{1}$, Gregor Hillers ${ }^{2}$ iD, and Olivier Gilbert ${ }^{1}$ \\ ${ }^{1}$ Institut des Sciences de la Terre, Université Grenoble Alpes, Grenoble, France, ${ }^{2}$ Institute of Seismology, University of \\ Helsinki, Helsinki, Finland
}

\begin{abstract}
Field data are needed for a better understanding of sea ice decline in the context of climate change. The rapid technological and methodological advances of the last decade have led to a reconsideration of seismic methods in this matter. In particular, passive seismology has filled an important gap by removing the need to use active sources. We present a seismic experiment where an array of 247 geophones was deployed on sea ice, in the Van Mijen fjord near Sveagruva (Svalbard). The array is a mix of $1 \mathrm{C}$ and 3C stations with sampling frequencies of 500 and $1000 \mathrm{~Hz}$. They recorded continuously the ambient seismic field in sea ice between 28 February and 26 March 2019. Data also include active acquisitions on 1 and 26 March with a radar antenna, a shaker unit, impulsive sources, and artificial sources of seismic noise. This data set is of unprecedented quality regarding sea ice seismic monitoring, as it also includes thousands of microseismic events recorded each day. By combining passive seismology approaches with specific array processing methods, we demonstrate that the multimodal dispersion curves of sea ice can be calculated without an active source and then used to infer sea ice properties. We calculated an ice thickness, Young's modulus, and Poisson's ratio with values $h=54 \pm 3 \mathrm{~cm}$, $E=3.9 \pm 0.15 \mathrm{GPa}$, and $v=0.34 \pm 0.02$ on $1 \mathrm{March}$, and $h=58 \pm 3 \mathrm{~cm}, E=4.4 \pm 0.15 \mathrm{GPa}$, and $v=0.32 \pm 0.02$ on 5 March. These values are consistent with in situ field measurements and observations.
\end{abstract}

\section{Introduction}

The effects of global climate changes are strongest in the Arctic, which is currently under-going the most intense warming of any region on Earth, for example, IPCC (2014). A spectacular signature of these changes is the accelerated decline of the sea ice cover, at a rate faster than that forecasted by climate models, both in terms of ice extent (Stroeve et al., 2007) or average thickness (Rampal et al., 2011). Significant multi-decadal trends are also observed for mechanically related variables, such as an acceleration of sea ice drift and deformation (Rampal et al., 2009) and a mechanical weakening at the Arctic basin scale (Gimbert et al., 2012).

Arctic sea ice has an influence on climate at the global scale, because of the key role it plays in several atmosphere-ice-oceans interactions, such as the thermohaline circulation in icy waters, or the Arctic oscillation (Chylek et al., 2009; Uttal et al., 2002). Positive feedbacks between sea ice decline, modification of the albedo of the Arctic ocean, and the warming of arctic waters, likely influences this evolution and may lead to a sea-ice-free Arctic in summer within few decades, an emblematic example of a climatic tipping point (Steffen et al., 2018; Stroeve et al., 2012). Hence, understanding this sea ice decline in conjunction with global warming is one of the main challenges of modern climatology. In this matter, a finer description of the dynamic and thermodynamic processes involved in sea ice models is needed. However, accurate parameterization of these models require more complete data sets of sea ice properties: salinity, temperature, mechanical properties, and thickness.

The use of seismic methods to study sea ice has been considered for more than 60 years. Sea ice acts as a waveguide for seismic waves. As such, it supports dispersive and multimodal wave propagation, which
(C)2020. American Geophysical Union. All Rights Reserved. 
Table 1

Sea Ice Properties and Thickness From Various Seismic Studies Between 1958 and 2019

\begin{tabular}{lccccc}
\hline & $S_{0}$ velocity $(\mathrm{m} / \mathrm{s})$ & $\mathrm{QS}_{0}$ velocity $(\mathrm{m} / \mathrm{s})$ & $E(\mathrm{GPa})$ & $v$ & Thickness (m) \\
\hline Anderson (1958) & $1,133-1,730$ & $1,960-2,990$ & $3.1-7.28$ & N/A & $0.15-1.3$ \\
Hunkins (1960) & $1,420-1,860$ & $2,400-3,080$ & $5.4-8.6$ & $0.29-0.38$ & $2.5-4.4$ \\
Pounder and Langleben (1964) & 1,788 & N/A & 7.19 & 0.25 & N/A \\
Miller and Schmidt (1991) & 1,590 & 3,090 & N/A & N/A & 1.2 \\
Yang and Giellis (1994) & 1,650 & 2,800 & 6.5 & 0.3 & 2 \\
Stein et al. (1998) & $1,550-1,650$ & $2,720-2,930$ & $6.1-7.2$ & 0.33 & 1.7 \\
Marsan et al. (2019) & 1,850 & N/A & N/A & N/A & N/A \\
\hline
\end{tabular}

can be used to estimate its mechanical properties and thickness. Pioneering works in this matter are the experiments by Anderson (1958), who inferred the elastic constants of the ice from seismic waves velocities, and by Hunkins (1960), who demonstrated the influence of temperature on the elastic constants of the ice, and used the dispersion of the flexural wave to estimate its thickness. Yang and Giellis (1994) measured broadband multimodal propagation, using a linear array of triaxial geophones and hammer blows. Stein et al. (1998) inferred the elastic properties and thickness of sea ice by inverting seismic data obtained with a similar experimental setup.

Table 1 compares sea ice properties measured from several sets of seismic data. Young's modulus extends between 3.1 and $8.5 \mathrm{GPa}$, and these should not be considered as the extremes values. These differences are, for the most part, essentially related to ice composition. Thinner and younger ice tends to be more porous and with a larger brine content (Weeks \& Ackley, 1986), resulting in lower values of Young's modulus (Mellor, 1986).

Due to the hostile environment and heavy logistics in polar regions, such studies have remained rare. With the need of exhaustive and accurate field data to meet the issue of climate change, and the rapid technological and methodological advances of the last decade, there has been a reconsideration of seismic methods for polar seismology (Kanao et al., 2015). In particular, passive seismology has addressed difficulties related to the need of active sources. Based on continuous recordings of the ambient seismic field, it is possible to turn seismic stations into virtual sources via basic signal processing (Sabra et al., 2005; Shapiro \& Campillo, 2004). This was recently applied for passive seismic studies of sea ice. Marsan et al. (2012) inferred Arctic sea ice thickness from measurements of the flexural wave dispersion. Sutherland and Rabault (2016) measured the dispersion and attenuation of the flexural wave in landfast ice. Marsan et al. (2019) observed the propagation of both the flexural and shear-horizontal waves from ambient seismic noise recordings in the Arctic.

The present paper follows up on our work initiated at the laboratory scale to infer the thickness and mechanical properties of the ice from the observation of guided wave modes (Moreau, Lachaud et al., 2017). In a layer of ice floating on water, the wavefield is composed of modes that are of the same nature as those that propagate in a stress-free plate, that is, the Lamb wave modes and the guided shear-horizontal (SH) wave modes. Lamb waves are decomposed in two families known as antisymmetric modes, $A_{n}$, and symmetric modes, $S_{n}$ (Lamb, 1917). We distinguish between the fundamental modes $(n=0)$ that propagate at all frequencies and the higher-order modes $(n=1,2,3, \ldots)$ that become propagative only at frequencies above their cutoff frequency. Antisymmetric modes produce an axial displacement component that is antisymmetric and a normal displacement component that is symmetric, with respect to the middle-plane of the plate. For symmetric modes, this is the opposite. As such, antisymmetric modes generate flexural motion, and symmetric modes generate traction-compression motion.

The solid-liquid interface, however, induces a change in the boundary conditions. This does not modify the propagation of the guided SH modes (because there is no coupling with shear motion in water), but it breaks the symmetry of the problem for the Lamb modes. As a consequence, the elastic wavefield in a free ice layer is different from that in a floating ice layer. The main differences are the existence of an additional mode, similar to the Scholte mode that propagates at the liquid-solid interface between two semi-infinite media, as well as a modification of the dispersion branches of the guided waves. For these reasons, the wavefield in 
(a)

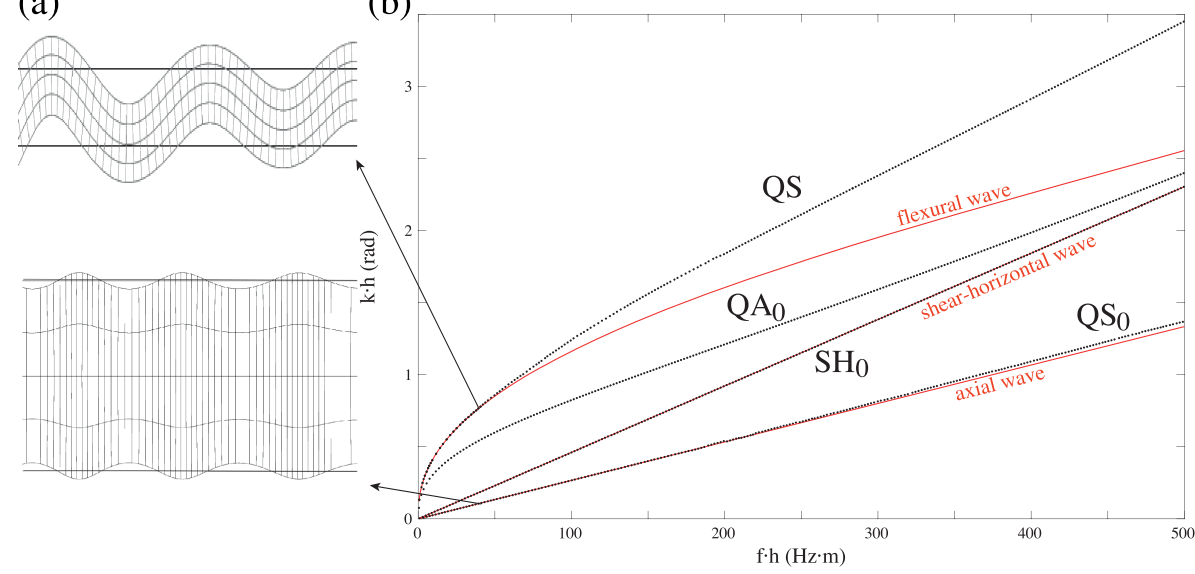

Figure 1. (a) Displacement field generated by the $Q S$ mode (top) and the $Q S_{0}$ mode (bottom) in a floating ice layer of thickness $h=50 \mathrm{~cm}$ at a frequency of $100 \mathrm{~Hz}$, with Young's modulus $E=4.5 \mathrm{GPa}$, Poisson's ratio $v=0.33$, and density $\rho=910 \mathrm{~km} / \mathrm{m}^{3}$. (b) Wavenumber-thickness versus frequency-thickness dispersion curves of the ice layer.

Black dots show the theoretical values and red lines the approximation of the $Q S$ and $Q S_{0}$ modes by the flexural and axial waves, which is valid when the frequency-thickness product is less than $50 \mathrm{~Hz} \cdot \mathrm{m}$.

a floating ice layer is referred to as quasi-symmetric $\left(Q S_{n}\right)$, quasi-antisymmetric $\left(Q A_{n}\right)$, and quasi-Scholte $(Q S)$ modes.

Below the cutoff frequency of the higher-order guided modes, the elastic wavefield in the ice is theoretically distributed on four propagating modes: $Q S, Q A_{0}, Q S_{0}$, and the fundamental shear-horizontally polarized mode $\left(\mathrm{SH}_{0}\right)$. The energy distribution of these modes on the displacement components depends on the product between the frequency of the exciting wavefield and the thickness of the ice. For example, when this product remains under $50 \mathrm{~Hz} \cdot \mathrm{m}$, most of the energy on the axial and transverse components comes from the $Q S_{0}$ and $S_{0}$ modes, while on the vertical component of the displacement the energy comes almost exclusively from the $Q S$ mode, because of the strong energy leakage of the $Q A_{0}$ mode in water. In such conditions, the wavefield can be approximated with only three propagating waves: the flexural wave, the axial wave, and the shear-horizontal wave (Stein et al., 1998). These are essentially the asymptotic behavior of the guided modes, when the displacement field across the ice thickness is considered linear for the QS mode and constant for the $Q S_{0}$ mode, as shown in Figure 1a. This approximation is valid only for frequency-thickness values under $50 \mathrm{~Hz} \cdot \mathrm{m}$. For higher values, the approximation no longer holds, and the dispersion branch of the $Q S$ mode starts to deviate from that of the flexural wave (Figure 1b). If frequency-thickness is increased further, the energy on the vertical component of the displacement becomes progressively dominated by the $Q A_{0}$ mode, the $Q S_{0}$ mode becomes dispersive, and higher-order modes become propagative (Moreau, Lachaud et al., 2017).

As far as seismology on sea ice is concerned, when active sources are used it is possible to measure wave propagation at frequency-thickness values exceeding $1000 \mathrm{~Hz} \cdot \mathrm{m}$. There have also been reports of higher-order modes propagating at lower frequency-thicknesses (Yang \& Giellis, 1994), although the origin of these modes could not be explained, because the maximum frequency-thickness was around $100 \mathrm{~Hz} \cdot \mathrm{m}$ values. For passive seismology (i.e., seismology without active sources), the majority of reports are for environments characterized by frequency-thickness below 0.5 Hz.m (Marsan et al., 2012; Sutherland \& Rabault, 2016), where wave excitation comes mainly from wind and swell. In this paper, we demonstrate that multimodal and broadband propagation of guided waves can be extracted far beyond this value from passive recordings and used to monitor sea ice properties. To this end, an array of 247 geophones was installed in the Van Mijen fjord (Svalbard) to record the ambient seismic field for 27 days. Recordings exhibit wave propagation at frequencies up to the sampling limit of $500 \mathrm{~Hz}$, with a level of energy showing that waves may propagate at even higher frequencies.

Using array processing methods, we analyze several aspects of this rich data set to demonstrate that passive seismic recordings on sea ice can produce results at least as good as active seismic experiments. In section 2, we introduce the array, the seismic acquisition, and the ground penetrating radar profiles. 
(a)

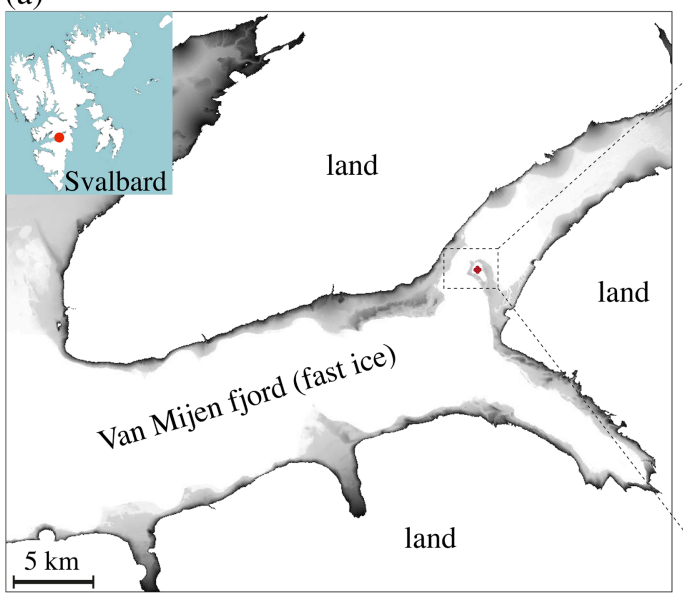

(b)

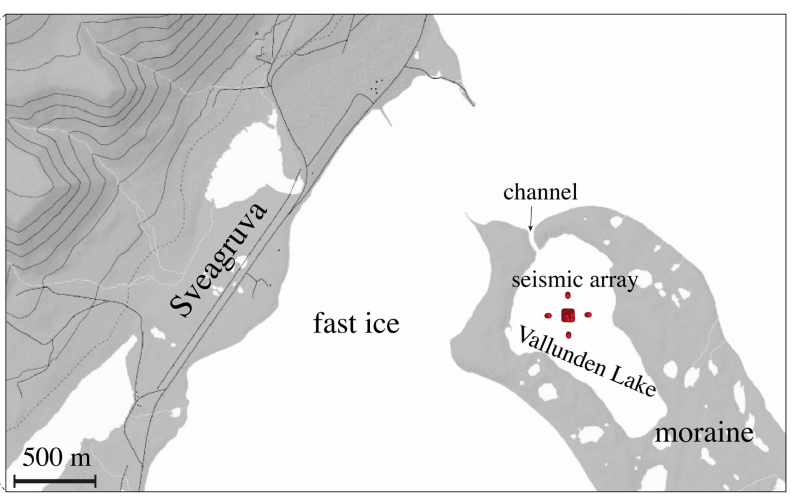

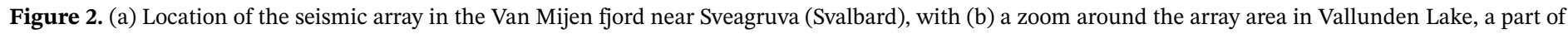

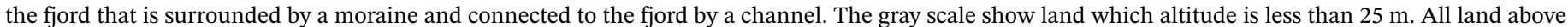
$25 \mathrm{~m}$ is shown in white to emphasize the shore line.

In section 3, we discuss the properties of the seismic wavefield and the dispersion curves of sea ice are calculated on 1 and 5 March 2019 from active sources, icequakes, and seismic noise. They are subsequently inverted for sea ice thickness, Young's modulus, and Poisson's ratio, yielding values that are consistent with in situ measurements and observations, as well as with previous reports on elastic properties for first-year ice.

\section{Material and Methods}

The aim of the deployment is to demonstrate that broadband propagation of guided waves can be extracted from passive seismic data measured in the ice and used to estimate ice thickness and its mechanical properties. A total of 247 FairFieldNodal Zland geophones (flat frequency response down to the cutoff frequency of $10 \mathrm{~Hz}$ for $1 \mathrm{C}$ and $5 \mathrm{~Hz}$ for 3C) were deployed on the ice of Van Mijen fjord in Vallunden Lake (Figure 2a). This part of the fjord, located $2 \mathrm{~km}$ south-east of Sveagruva, is surrounded by a moraine (Figure 2b). Because of its connection to the fjord by a canal of width $\sim 10 \mathrm{~m}$, Vallunden Lake is subject to tidal flows and forcing. It is a quiet zone that is well suited for scientific experiments on sea ice. Each node is equipped with a spike for better coupling with the ground. However, this is not ideal in the ice. Instead, the nodes were installed directly in the ice without their spike. To maximize the coupling, a milling tool was specifically designed to drill the ice at the diameter of the nodes. They were installed in the holes at about half their height and covered back with snow to insulate them for preserving their battery life. At the time of the deployment, the internal temperature of several nodes was measured, before and after covering them with snow, showing an increase from -21 to $-16^{\circ} \mathrm{C}$.

\subsection{Array Deployment}

Recording the three components of the displacement is technically not necessary to measure the $Q S$ and $Q S_{0}$ modes. However, the fundamental shear-horizontal $\left(\mathrm{SH}_{0}\right)$ mode can be measured only on the horizontal channels. Moreover, the $Q S_{0}$ mode is easier to measure on the horizontal channels, because it produces a weak vertical displacement at frequency-thickness values below $1000 \mathrm{~Hz} \cdot \mathrm{m}$. Therefore, in practice the use of $3 \mathrm{C}$ geophones helps with data interpretation. However, due to limited geophones availability, the deployment contains both $1 \mathrm{C}$ and $3 \mathrm{C}$ stations. We set the sampling frequency of the $1 \mathrm{C}$ and $3 \mathrm{C}$ stations to 500 and $1000 \mathrm{~Hz}$, respectively. A consistent sampling rate of $1000 \mathrm{~Hz}$ was prohibitive because of the shorter battery life of the $1 \mathrm{C}$ geophones.

The geophones were divided into five zones, including one large, two-dimensional array, and four smaller linear arrays. The distribution of the sensors is presented in details in Figures 3a and 3b, with blue and red dots indicating $1 \mathrm{C}$ and $3 \mathrm{C}$ geophones. The main array is a large squared area with sides of length $48 \mathrm{~m}$ (Figure 3b). The other four arrays consist of four stations with an aperture of $12 \mathrm{~m}$. It is noteworthy that, during deployment, a $1 \mathrm{C}$ geophone was replaced with a spare $3 \mathrm{C}$ sensor because it was deficient (see station 133-517 in Figure 3b). Moreover, stations 113-509 and 125-542 (marked with a cross in Figure 3b) were deployed but failed to record, which leaves the main array with 231 operating sensors. The purpose of the 

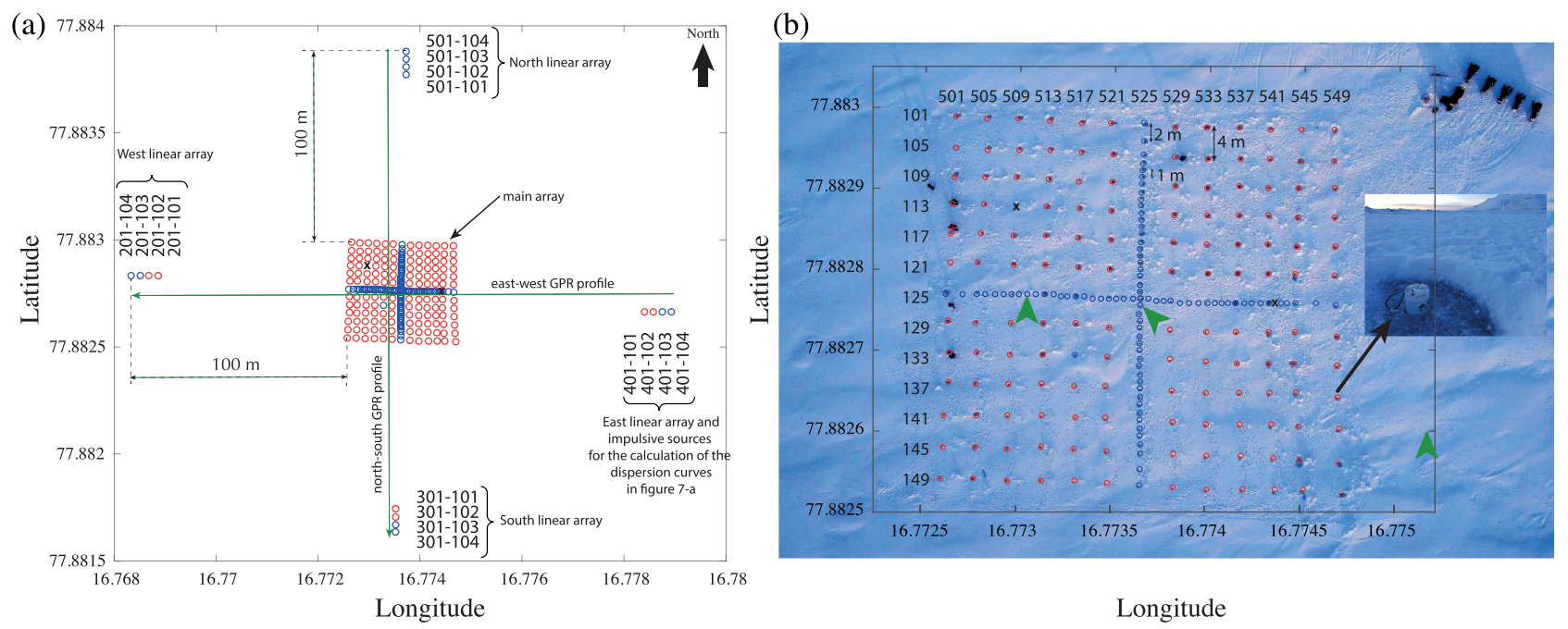

Figure 3. (a) The 247 stations of the array, including the main central array, and the four linear arrays to the north, east, south, and west. Arrows indicate the positions of the two GPR profiles. (b) Aerial view of the main array, with station numbering and a photo of one geophone lines. Geophone station numbers are given as intersection numbers of east-west and north-south profiles. The two crosses indicate stations that were installed but failed to record: $125-542$ and 113-509. Station 133-517 was originally a 1C station but was replaced by a spare 3C station due to technical problems. Red circles are for 1C stations and blue circles for $3 \mathrm{C}$ stations. The large arrowheads indicate the positions of ice thickness measurements.

main array is to measure guided waves propagating in all directions. The linear arrays act as distant virtual sources, for the calculation of the noise correlation functions (Sabra et al., 2005; Shapiro \& Campillo, 2004).

Based on an ice thickness of $50 \mathrm{~cm}$, the spatial sampling of the $1 \mathrm{C}$ geophones in the main array $(4 \mathrm{~m})$ is sufficient to measure the slowest mode, $Q S$, and the fastest mode, $Q S_{0}$, in the $1-20 \mathrm{~Hz}$ and $30-250 \mathrm{~Hz}$ frequency ranges, respectively. With the denser spatial sampling of the $3 \mathrm{C}$ geophones $(1 \mathrm{~m})$, these two modes can be measured in extended frequency ranges: $1-150 \mathrm{~Hz}$ for $Q S$ and $30-500 \mathrm{~Hz}$ for $Q S_{0}$. This high spatial density is not necessary for monitoring ice thickness and mechanical properties, because the guided wave inverse problem is very well constrained. The quality of the inversion depends essentially on the number of modes that can be measured and the bandwidth on which they are measured. The more modes and the larger this bandwidth, the better constrained the inversion. The $S H_{0}$ mode is not dispersive, and the $Q S_{0}$ mode becomes dispersive only at much higher frequency-thickness values (above $1000 \mathrm{~Hz} \cdot \mathrm{m}$ ). If the $Q S$, $Q S_{0}$, and $\mathrm{SH}_{0}$ modes can all be measured, then a well-constrained inversion can be expected even in narrower frequencies bands, for example, in the 1-5 Hz bandwidth. In that case, a spatial sampling of 10-15 m could be sufficient. Of course, for sea ice with a thickness $x$ times greater than that at Vallunden Lake, the spatial sampling can be reduced by the same factor $x$. One of the objectives of this experiment is to underpin research on the trade-off between accuracy and array density and should help setting new benchmarks for future inversions of sea ice seismic data.

\subsection{Field Acquisitions}

\subsubsection{Ice Drillings}

Sea ice thickness was measured in the fjord on 1 March 2019, $10 \mathrm{~m}$ east of station 141-549. A thickness of $62 \mathrm{~cm}$ was measured. It was also measured on 26 March next to stations 125-511 and 126-525, giving a thickness of 70 and $73 \mathrm{~cm}$. Around position N77.8845 ${ }^{\circ}$ E16.776 , about $170 \mathrm{~m}$ north of station 101-549, several measurements by another group of researchers gave ice thicknesses that varied between 75 and $80 \mathrm{~cm}$ between 4 and 16 March 2019. This indicates substantial spatial and temporal thickness variations of the ice cover at Vallunden Lake.

\subsubsection{Ground Penetrating Radar Survey}

On 28 February 2019, two linear GPR profiles were acquired over a distance of $250 \mathrm{~m}$ with $800 \mathrm{MHz}$ shielded antenna of Mala Geosciences: a north-south profile between stations 501-104 and 301-104 and an east-west profile between stations 401-104 and 201-104. Both GPR profiles were processed with a $450-1100 \mathrm{MHz}$ band-pass filter and late arrivals amplification with a time squared gain function. Figure 4 shows the resulting processed images for both profiles, which are dominated by the air wave followed by a large reflection, whose first onset varies between 2 and 3 ns along the profile. This could represent the base of the snow cover. 
(a)

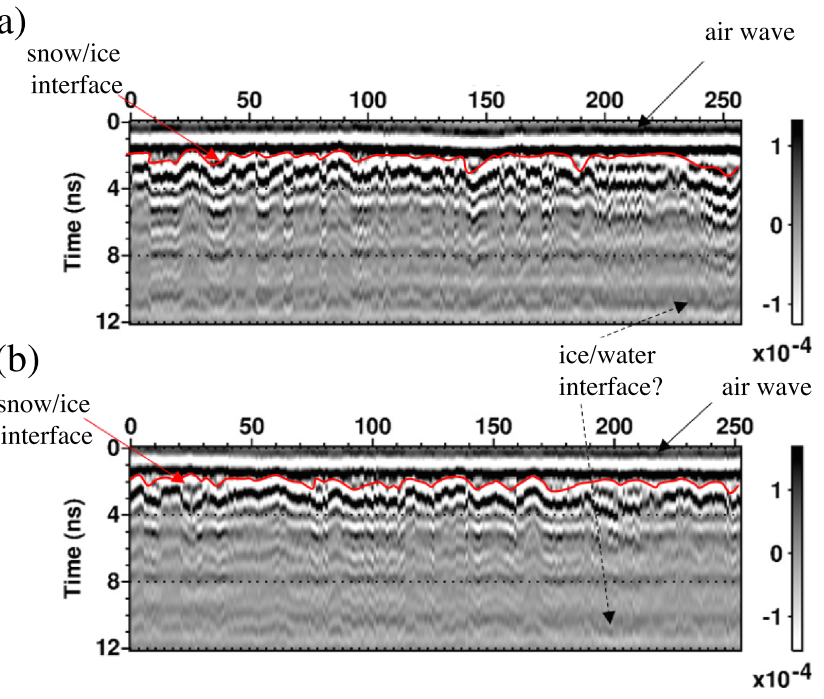

distance along profile $(\mathrm{m})$

Figure 4. Processed ground penetration radar profiles acquired on 28 February 2019 along the (a) north-south direction between stations 501-104 and 301-104 and (b) east-west direction between stations 401-104 and 201-104 (see Figure 3a for exact profiles locations).
This large event is followed by other reflections with the same polarity, which might be multiples. An additional waveform, which arrives around $10 \mathrm{~ns}$, exhibits slight variations with an opposite reflectivity. This could indicate the reflection at the sea ice/sea water interface but with these GPR data, such interpretation remains speculative.

The velocity of electromagnetic waves in snow strongly depends on its properties (Liu et al., 2014) and ranges from $16.8 \mathrm{~cm} / \mathrm{ns}$ (highly dense compacted snow with a very weak porosity) to $25.5 \mathrm{~cm} / \mathrm{ns}$ (very porous fresh snow). In the absence of any common middle point acquisition, we use an average velocity of $21.1 \mathrm{~cm} / \mathrm{ns}$. From this estimate, the snow thickness varies between $21.1 \mathrm{~cm}(2 \mathrm{~ns})$ and $32.2 \mathrm{~cm}(3 \mathrm{~ns})$, which is consistent with observations in the field, despite a large uncertainty of $\pm 20 \%$.

In sea ice, the velocity may vary between 10.6 and $15 \mathrm{~cm} / \mathrm{ns}$, depending on its brine content and temperature. Assuming an average velocity of $12.8 \mathrm{~cm} / \mathrm{ns}$, the second reflection would correspond to an ice thickness around $52 \mathrm{~cm}$ with a large uncertainty of $\pm 17 \%$. This range is consistent with the local drilling information $(62 \mathrm{~cm})$ and with estimates from seismic methods ( $54 \mathrm{~cm}$, see section 3.5 ). Here, the interpretation of the GPR images appears speculative and uncertain. As noted by Liu et al. (2014) this problem appears when high-frequency antennas are used, because the high conductivity of sea ice drastically decreases the penetration of a GPR signal. Consequently, if GPR is able to detect the snow cover with a good resolution, the detection of sea ice bottom remains uncertain and strongly depends on the saline properties of sea ice, which is not the case with seismic methods.

\subsubsection{Vibrating Sources, Impulsive Sources, and Artificial Noise Sources}

A series of active seismic experiments was conducted on 1 and 26 March 2019, at the times and positions indicated in Table A1, including vibrating and impulsive sources. Vibrating sources are 10, 15, and $60 \mathrm{~s}$ sweeps with a shaking device at frequencies varying between 1 and $450 \mathrm{~Hz}$. Impulsive sources are person weight ( $80 \mathrm{~kg}$ ) drops (jumps) from $1 \mathrm{~m}$ height onto the ice. Moreover, artificial seismic noise was created by driving five snowmobiles around the array for several minutes. The first driving sequence was on 1 March 2019 between 14:25 and 14:30, and the second on 26 March 2019, between 15:49 and 15:54 (UTC).

The vibrating sources and artificial noise will be useful for future in-depth analyses of signals with correlation-based processing methods. For example, snowmobiles are a relatively high-frequency seismic noise source, up to $\sim 200 \mathrm{~Hz}$. Such acquisitions are therefore of interest for investigating the convergence of the noise correlation function.

Note that, in this section, we are introducing the full seismic experiment so that it can be referred to in our future works on this rich data set. However, in the following, only the impulsive sources to the east of the main array are considered, that is, those located at stations 401-101 to 401-104 (see Figure 3a). The purpose here is twofold. First, we are demonstrating that the dispersion curves obtained with passive data are comparable to those obtained with active sources. Second, we are demonstrating that the noise correlation function converges quickly toward the Green's function of the ice layer, and by extension that it can be used for monitoring ice properties with a temporal resolution that is less than a day.

\section{Results}

3.1. Noise Properties: Power Spectral Density

Figure 5 shows the spectrogram of one full day of recording on 5 March 2019, from station 125-525 at the center of the main array. The spectrogram contains thousands of impulsive and broadband events. Part of these events are probably due to the specific conditions of the ice at the Lake, where it is directly in contact with the shores and influenced by the mechanical stress induced by tidal effects. For example, tidal cracks were observed along the shoreline. Some cracks were frozen or some partially frozen, depending on the tidal phase. Water in and outflow through the connecting channel had a maximum speed of $3 \mathrm{~m} / \mathrm{s}$ and probably contributed to the triggering of icequakes too. However, because they occur at any time and on every day, it is fair to assume that there is also a large amount that is not connected to the specific situation at the lake. 


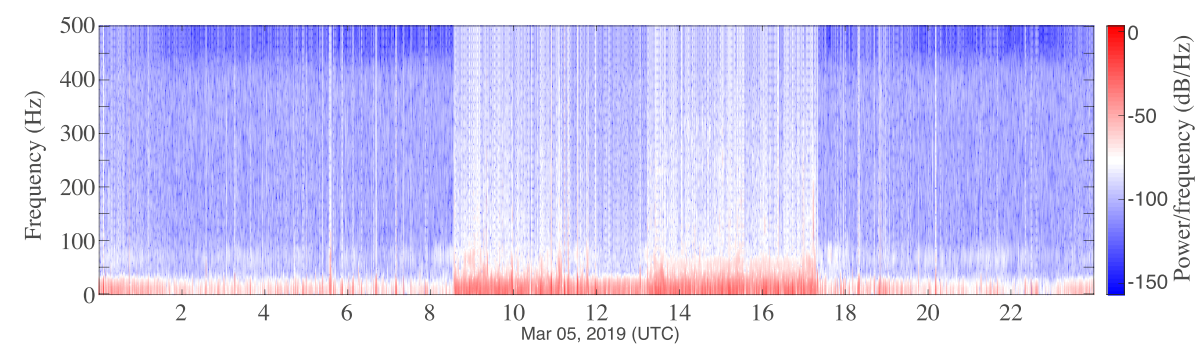

Figure 5. Spectrogram of the signal recorded at the center of the main array by station 125-525 on 5 March 2019. Hundreds of broadband events are recorded every hour. The increase of activity between 8:30 and 17:30 corresponds to field work on the lake.

For the same reason, it is also fair to assume that many icequakes also happen in freely floating sea ice, where plate inner deformation due to relative drift, swell, and thermal expansion of the ice, are known to induce cracking.

There is also a more consistent trend at lower frequencies between 1 and $25 \mathrm{~Hz}$, where signal exhibits stronger energy levels. The origin of this seismic noise is a mix between wind and water current, under the ice, in the canal. Note the presence of more energetic signals between 8:30 a.m. and 5:30 p.m. They were generated by research field works that took place about $300 \mathrm{~m}$ north-east of the main array. They lasted 12 days, between 4 and 16 March 2019. Since these noise sources are not natural and very directional, they are not of interest for this study and will be disregarded in the following. Therefore, next we focus on data recorded in the absence of human activity.

\subsection{Noise Properties: Wavefield Isotropy}

In order to identify the azimuthal distribution of the wavefield around the array, we apply classical beamforming to the data. This processing aims at investigating a seismic wavefield in terms of its directionality and phase slowness, based on its spatial coherency across an array (Rost \& Thomas, 2002). When applied to a full day of data, it provides insights in the origin of the seismic noise. When applied to a few seconds of data, this allows the identification of impulsive microseismic events as well as their direction of propagation. In practice, beamforming consist of delaying the waveforms with the phase slowness of a plane wave propagating through the array with a given azimuthal direction, and summing the resulting signals. The slowness and angle that return the maximum output are closest to those of the wavefield recorded in the time window.

Because beamforming relies on the spatial coherency of the wavefield, it is sensitive to spatial sampling. As such, it is restricted to frequencies where geophones spacing allows a sampling of the wavelength that satisfies Nyquist's criterion to prevent aliasing. Spatial sampling in the main array is limited by the 1C stations, separated with a 4-m spacing. We are therefore restricted to frequencies where the wavelength is at least $8 \mathrm{~m}$, that is, under $16 \mathrm{~Hz}$ for the $Q S$ mode.

We applied this processing to $12 \mathrm{hr}$ of noise recording without nearby human activity on 3 March 2019 between 0 h00 and 12h00. Figure 6 shows the beamforming obtained from the vertical displacement in four frequency bands: $3-5,7-9,11-13$, and 15-17 Hz. This displacement component is strongly dominated by the QS mode at such frequencies; hence, the beamformer is mainly associated with this mode. Consequently, the aliasing limit mentioned previously is visible in the $15-17 \mathrm{~Hz}$, where beamformer overlapping starts to occur near a slowness of $8 \mathrm{~s} / \mathrm{km}$.

The circular amplitude of the beamformer around the array center indicates that noise sources are distributed in all azimuthal directions. The intensity is slightly lower to the south of the array. This is likely the consequence of the array position relative to the edges of the lake, which are closer to the north, east, and west than they are to the south. Hence, waves emitted from the southern part of the lake may have a lower amplitude due to more energy leakage in water. The isotropic ambient wavefield allows to look for specific microseismic events to act as sources that originate from a desired direction, in view of computing the dispersion curves of sea ice.

\subsection{Typical Microseismic Events}

In this section, we focus on the first $8 \mathrm{hr}$ of recording on 5 March 2019. The corresponding signal is shown in Figure 7 for station 125-525. It contains hundreds of events with amplitudes that vary by up to two orders 

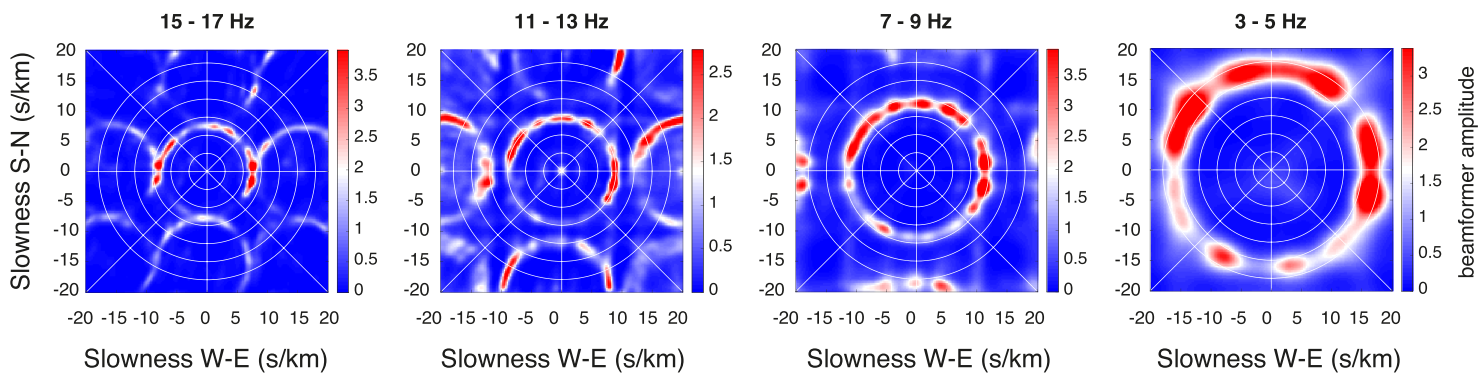

Figure 6. Beamforming of one full day of ambient seismic noise recorded on 3 March 2019. The distribution of noise sources is isotropic, with a slightly lower amplitude to the south. Note the aliasing limit in the $15-17 \mathrm{~Hz}$ frequency band, where the $Q S$ mode has a wavelength of about $8 \mathrm{~m}$, causing a duplication of the beamformer that is very close to overlapping itself near the slowness of $8 \mathrm{~s} / \mathrm{km}$.

of magnitude, as shown in the zoom between 1:30 and 2:30 a.m. By scanning this signal with 4-s-long moving time window and applying beamforming to the data, it was possible to identify events with significant amplitude that originated from the east. Three of such events are shown in color in Figure 7. The figure also shows the beamforming associated with the third event. It was computed in the 15-17, 11-13, 7-9, and 3-5 Hz frequency bands, resulting in a velocity of 139, 118, 93, and $60 \mathrm{~m} / \mathrm{s}$, respectively, which reveals the strong dispersion of the signals.
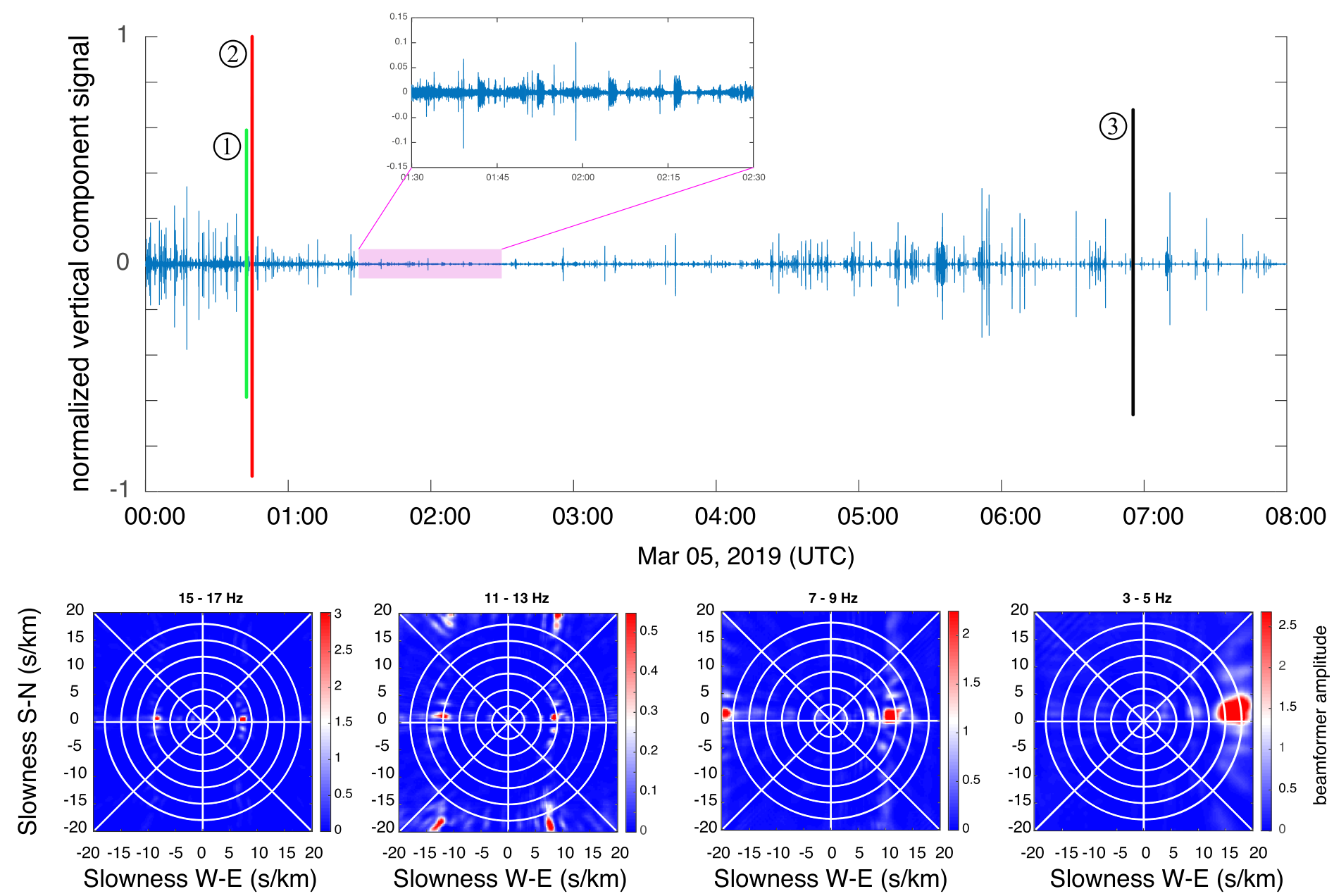

Figure 7. Top: $8 \mathrm{hr}$ of recording from the vertical component of station 125.525 on 5 March 2019 with a zoom between 1:30 and 2:30 a.m. Colored signal indicates events 1,2, and 3 used to compute the dispersion curves of the ice (see Figure 9). Bottom: Beamforming of the data from event 3 in the 15-17, 11-13, 7-9, and 3-5 Hz frequency bands. 

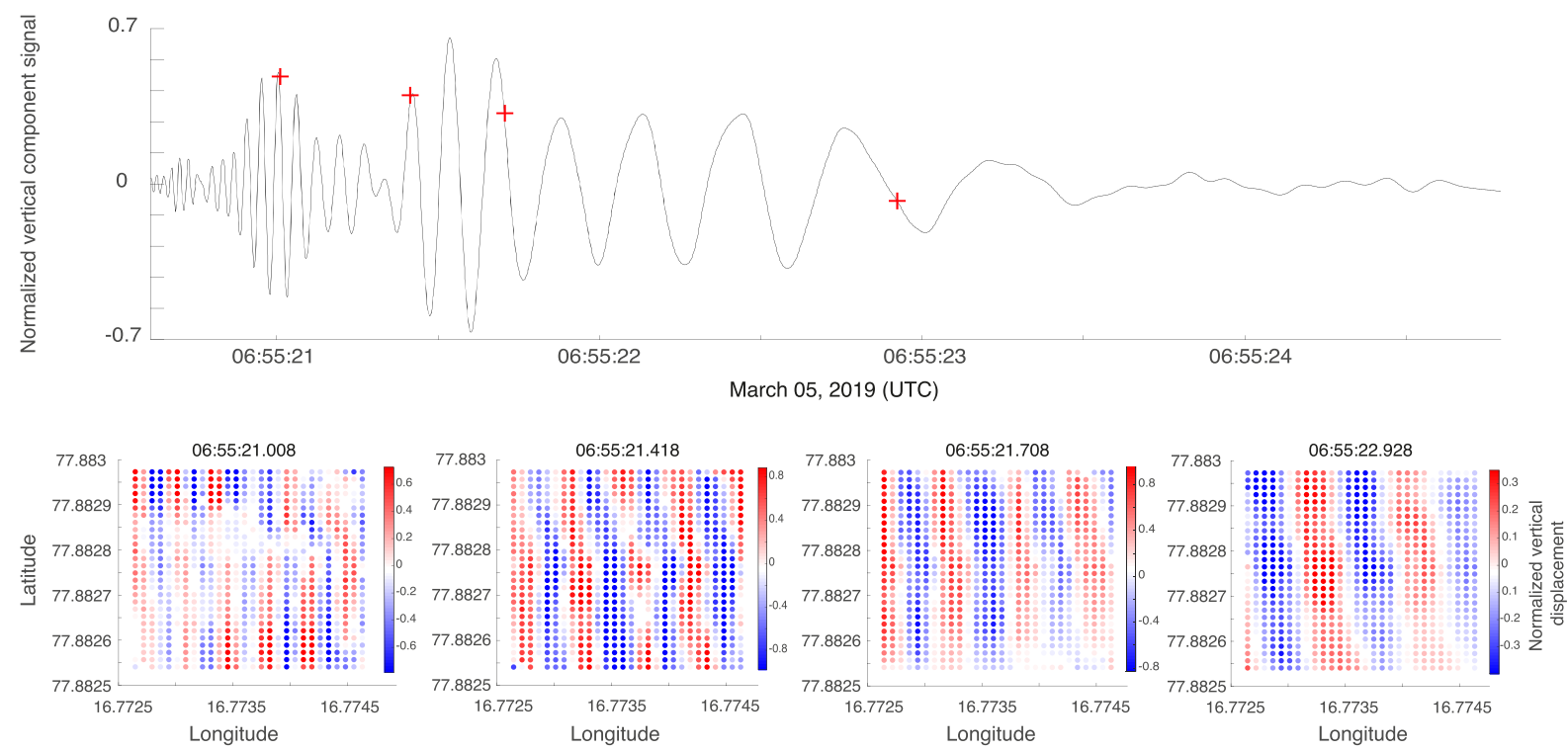

Figure 8. Top: zoom on the third event isolated in Figure 7. Bottom: representation of the vertical displacement component through the main array at the times marked with a red cross in the signal. Higher frequencies arrive before the lower frequencies, which is typical of the $Q S$ mode.

Figure 8 shows a zoom on event 3, as well as the distribution of the vertical displacement component in the main array. These snapshots of the wavefield were extracted at the times marked with a red cross in event 3. For better visualization, data were first interpolated on a denser grid with a 1-m interval. This is a clear visualization of seismic wave dispersion in sea ice, with high frequencies arriving first, which is typical of the $Q S$ and $Q A_{0}$ modes at low frequencies-thickness values. It is noteworthy that for values of the order of $1 \mathrm{~Hz} \cdot \mathrm{m}$, the displacement is dominated by the $Q S$ mode on the vertical component, the $Q S_{0}$ mode on the radial component, and the $S H_{0}$ mode on the horizontal component. Hence, the $Q A_{0}$ mode contributes to the wavefield with a negligible effect, and the high dispersion observed in the beamforming is that of the $Q S$ mode, which is used next to estimate ice thickness.

\subsection{Dispersion Curves of Sea Ice}

In this section we calculate the frequency-wavenumber spectrum of the waveforms propagating along line 125 of the main array, where the denser spatial sampling allows measurements without aliasing up to $150 \mathrm{~Hz}$ for the three modes. This analysis is performed on 1 and 5 March 2019 to recover the dispersion curves of sea ice, based on the wavefield generated by active sources and icequakes, or the wavefield reconstructed from the seismic noise via correlation methods. We outline specific array processing that takes advantage of the multiplicity of sources for enhanced calculation of the dispersion curves.

\subsubsection{Array Processing for Calculating Dispersion Curves}

A classical way of computing the dispersion curves of a wavefield is to apply a Fourier transform to the time and space dimensions of the waveforms recorded along a line of geophones, which yields the frequency-wavenumber spectrum. If several sources are available, the spectra can be averaged over the number of sources. However, signals with a low signal-to-noise ratio (SNR) may result in frequency-wavenumber spectra of poor quality. A better way of taking advantage of several sources consists in combining them, following the processing described in Minonzio et al. (2010). The reader is referred to Minonzio et al. (2010) and Moreau, Lachaud et al. (2017) for more details regarding its implementation and application to the present problem. Only the main steps of this processing are outlined here.

1. The matrix of transmit-receive signals has three dimensions: sources, receivers, and time. The first step is the application of the Fourier transform to the temporal dimension of this matrix.

2. At each frequency, the resulting Fourier-domain matrix is sliced into two-dimensional transmit-receive matrices. These matrices are then decomposed into singular values, with the underlying idea that the different levels of modal energy are distributed onto a set of orthogonal singular vectors. This allows a heuristic separation of the noise and signal subspaces, in a classical way for singular value-based filters.

3. The last step consists of defining test vectors that are representative of the wave propagation problem in the receivers basis, for example, plane waves with a given wavenumber. The projection of test vectors onto the 
(a)

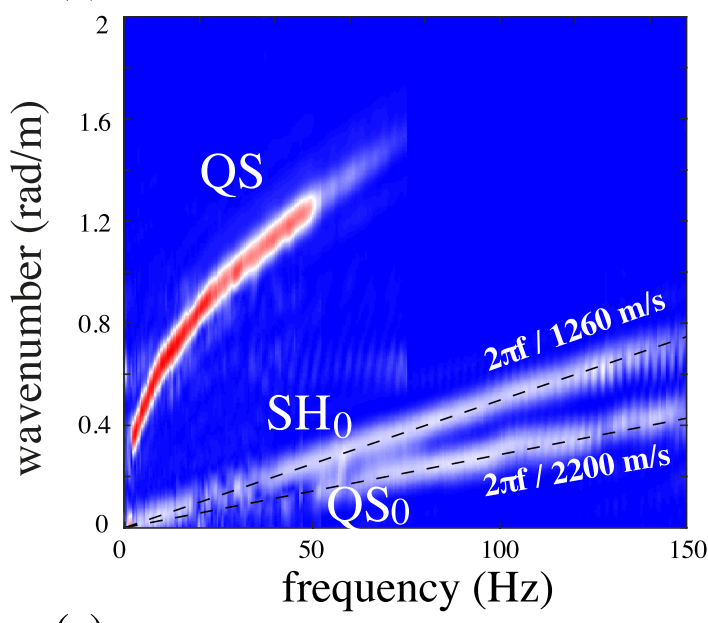

(c)

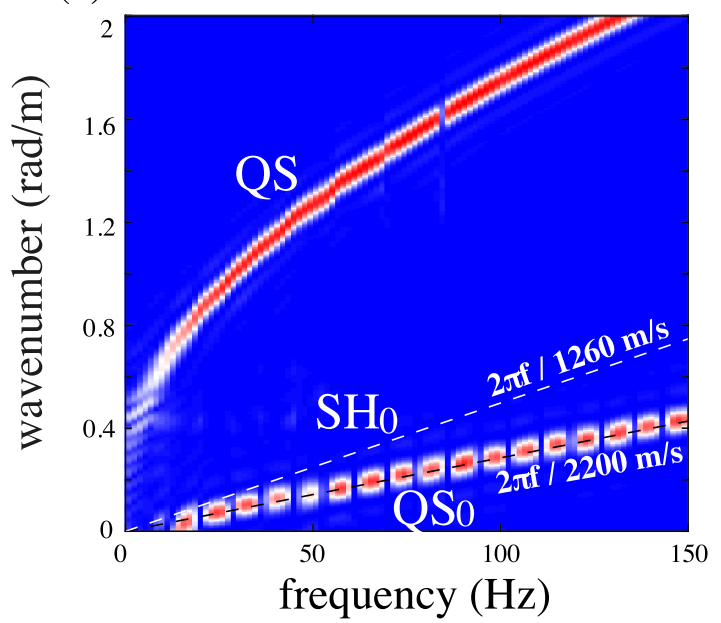

(b)

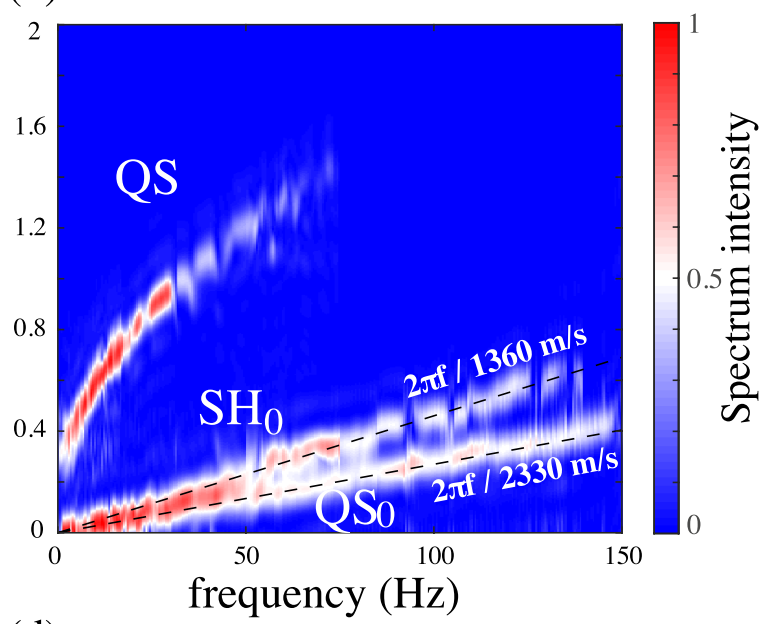

(d)

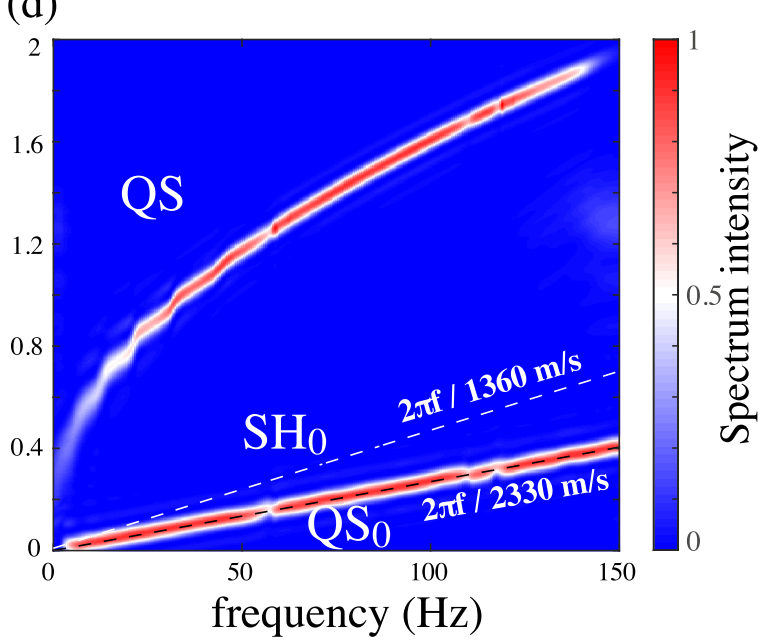

Figure 9. (a, b) Dispersion curves of the ice at Vallunden Lake obtained using the three displacement components measured along row 125, from (a) the four impulsive sources to the east of the main array on 1 March 2019 and (b) the propagation of the three events isolated on 5 March 2019 (Figure 7). (c) Dispersion curves obtained from the two displacement components of a two-dimensional finite element simulation of seismic waves propagating in a layer of floating ice with a thickness of $h=54 \mathrm{~cm}$, Young's modulus $E=3.9 \mathrm{GPa}$, Poisson's ratio $v=0.34$, and density $\rho=910 \mathrm{~kg} / \mathrm{m}^{3}$. (d) Same as (c) with $h=58 \mathrm{~cm}, E=4.4 \mathrm{GPa}$, Poisson's ratio $v=0.32$, and density $\rho=910 \mathrm{~kg} / \mathrm{m}^{3}$.

singular vectors of the receivers basis leads to a scalar product that is maximized when the wavenumber in the test vector matches that of the waves in the measured wavefield.

This processing significantly enhances the identification of the dispersion branches in the frequency-wavenumber space, for two reasons: (i) the separation of the noise and signal subspaces and (ii) the projection of test vectors is not weighted by singular values. Yet the energy information is only contained in singular values, not in singular vectors, which all have a norm equal to unity. Hence, in theory all modes stand out with the same spectrum intensity, despite their different relative energy in the wavefield.

\subsubsection{Dispersion Curves of Sea Ice from Passive and Active Seismic Events}

The first data set used for computing the dispersion curves is the matrix of signals recorded during the $5 \mathrm{~s}$ following the active impulsive sources at stations 401-101 to 401-104, on 1 March 2019. The second data set is the matrix of signals recorded on 5 March 2019 during the $5 \mathrm{~s}$ of propagation of the three microseismic events shown in Figure 7. They exhibit energy at frequencies from $0 \mathrm{~Hz}$ up to at least the sampling limit of $500 \mathrm{~Hz}$. These events all originate from a direction that almost coincides with that of line 125 , the difference being less than $7^{\circ}$. Hence, from the apparent wavenumber measured along the stations in row 125 during the propagation of these events, the wavenumber of the guided modes propagating in the actual east-west direction can be estimated with less than $1 \%$ error. A first attempt at calculating the dispersion branches was made by applying a classical frequency-wavenumber Fourier transform to the data sets, and averaging the 
spectra over the number of sources. Only the $Q S$ appears clearly in the resulting diagrams, in a frequency band limited between 5 and $35 \mathrm{~Hz}$. The $Q S_{0}$ mode is barely visible, and the $S H_{0}$ mode is not detected (see Figures B1-a and B1-b). This is essentially due to the fact that most of the energy goes to the QS mode at these frequency-thickness values, and to energy leakage in water.

Application of the processing described in section 3.4.1 to the three components of the displacement significantly enhances the dispersion curves. The resulting diagrams for the active and passive data sets are shown in Figures 9a and 9b.

These dispersion curves can be converted into modal velocities, using the following three-step process.

1. For each frequency, extract the couples $\left(f_{m}, k_{m}\right)$ with maximum intensity in the dispersion curves. This is performed for the three modes: $m=Q_{S}, Q_{S_{0}}, S H_{0}$.

2. Convert the frequency-wavenumber couples, $\left(f_{m}, k_{m}\right)$, into frequency-velocity couples, $\left(f_{m}, c_{m}\right)$, with $c_{m}=$ $2 \pi f_{m} / k_{m}$.

3. For each mode, find the best fit of all $\left(f_{m}, c_{m}\right)$ couples. $S_{0}$ and $S H_{0}$ are not dispersive at the frequencies of interest; hence, we used linear interpolation. For the $Q S$ mode, however, we used spline interpolation to account for the nonlinear pattern.

It is also possible to calculate the standard deviation of the absolute error of the interpolations. The extracted velocities and the histogram of the interpolation error are shown in Figure C1. In the following we use these standard deviations as a measure of uncertainty for the velocities. They are also converted into the standard deviation of the estimated Young's moduli, Poisson's ratios, and thicknesses.

From the active data set recorded on 1 March 2019, we measure nondispersive propagation of the $S H_{0}$ and $Q S_{0}$ modes at a velocity of 1,260 \pm 15 and 2,200 $\pm 84 \mathrm{~m} / \mathrm{s}$, respectively, while the $Q S$ mode propagates with a velocity varying between $58 \pm 1 \mathrm{~m} / \mathrm{s}$ at $4 \mathrm{~Hz}$ and $277 \pm 1 \mathrm{~m} / \mathrm{s}$ at $60 \mathrm{~Hz}$. From the passive data set recorded on 5 March 2019, we measure nondispersive propagation of the $S H_{0}$ and $Q S_{0}$ modes at a velocity of $1,360 \pm 48 \mathrm{~m} / \mathrm{s}$ and $2,330 \pm 63 \mathrm{~m} / \mathrm{s}$, respectively, while the $Q S$ mode propagates with a velocity varying between $60 \pm 2 \mathrm{~m} / \mathrm{s}$ at $4 \mathrm{~Hz}$ and $287 \pm 2 \mathrm{~m} / \mathrm{s}$ at $60 \mathrm{~Hz}$.

These velocities correspond to an apparent wavefield propagating under the array. Therefore, any variations of ice thickness or elastic properties along the array are averaged in the frequency-wave number diagram. It is possible to account for thickness variations (Moreau et al., 2014) and potentially for variations of elastic properties as well, using more advanced signal processing, but this is out of the scope of this paper and is left for future investigations. The variations of guided modes velocities between 1 and 5 March 2019 demonstrate the high sensitivity of the dispersion curves to ice thickness and elastic constants. This property of the guided wave modes are in favor of a very well-constrained inverse problem, which is actually already used extensively a the ultrasonic scale, in the fields of nondestructive testing and medical ultrasound to estimate bone mechanical resistance and thickness.

\subsubsection{Dispersion Curves of Sea Ice From the Noise Correlation Function}

Because it might not always be possible to isolate suitable icequakes for estimating sea ice properties, an alternative is to use the so-called noise correlation function (NCF). Historically, ambient seismic noise was used to qualify the contribution of all unwanted sources that corrupt the quality of conventional seismic recordings. For example, microseismic events or human activity generate broadband seismic noise, while wind or swell generate low-frequency noise. In passive seismology, the NCF is calculated by correlating the ambient seismic noise (or ambient seismic field) recorded between station pairs. It can be shown that it converges toward the impulse response, or Green's function, of the medium (Sabra et al., 2005; Shapiro \& Campillo, 2004). Because the NCF integrates the contribution of all noise sources, impulsive or more stationary, it naturally results in more energetic signals with a broader frequency content than those from isolated events. The aim of this section is to demonstrate that one can achieve results from the NCF that are at least as good as those obtained from icequakes or active sources.

As shown in section 3.2, the ambient seismic field is isotropic at the scale of a few hours. This is ideal for the convergence of the NCF. The impulse response of the ice is known on 1 March 2019 from the impulsive active sources (jumps). Hence, for comparison we use the seismic noise recorded on the same day, from 0h00 to 12h00, at the stations of the linear array to the east (stations 401-101 to 401-104) and those of line 125 of the main array. Stations of the linear array are used as virtual sources, and those of line 125 are used as the receivers. Recordings were first split in 30-min time windows, and spectral whitening was applied in 

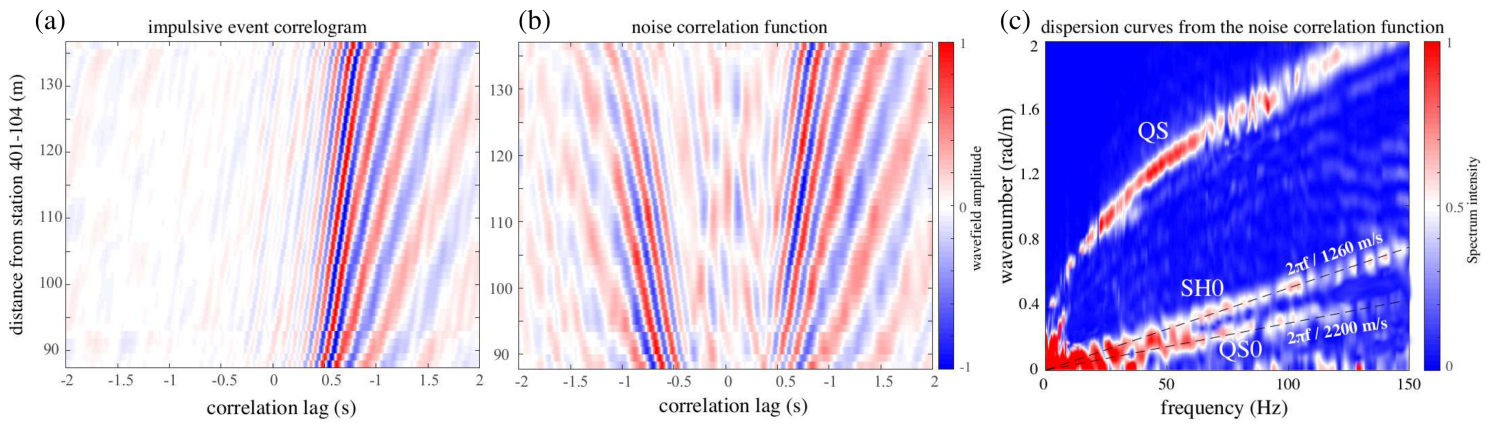

Figure 10. (a, b) Correlograms between station 401-104 and the stations of line 125 in the array, filtered in the 1-10 Hz frequency band for better visualization purpose. (a) correlations from the ambient wavefield recorded for $12 \mathrm{hr}$ on 1 March 2019. (b) Correlations from signals recorded during the $5 \mathrm{~s}$ following the impulsive source at station 401-104 on 1 March 2019. (c) Dispersion curves of the ice at Vallunden Lake along line 125, obtained from the NCF of the three displacement components with the stations of the east linear array as virtual sources.

the $1-150 \mathrm{~Hz}$ frequency band. The cross-correlations were then calculated between each virtual source and all the receivers, resulting in 24 cross-correlations for each stations pair. To obtain the final NCF, the filter introduced in Moreau, Stehly et al. (2017) was applied to each set of cross-correlations, which were finally stacked. The purpose of this filter is to minimize the incoherent information in the singular vectors of the matrix of pre-stack correlations with the Wiener filter, for improved convergence of the NCF. An example of NCF from the vertical displacement component is shown in Figure 10b when the virtual source 401-104 is used.

For comparison, the Green's function between the same stations pairs was estimated by correlating signals recorded in the $5 \mathrm{~s}$ following the impulsive active sources, located exactly at the position of the virtual sources used for the NCF. This is shown in Figure 10a for the vertical displacement from the impulsive source at station 401-104. Note that the signals shown in Figures 10a and 10b are filtered in the 1-10 Hz frequency band, for visualization purposes. The causal and a-causal part of the NCF are symmetric, a typical feature that is expected when the source distribution is isotropic. There is a very good agreement between the causal part of the NCF from virtual source 401-104 and the response from the active impulsive source at the same station, indicating convergence of the NCF. By reciprocity, the a-causal parts of the NCF converge toward the Green's function propagating in the opposite direction. Note the strong dispersion of the waveforms, typical of the $Q S$ mode. This was expected because the vertical displacement is dominated by this mode in this frequency band.

Based on these observations, and also on the fact that noise sources are broadband, with energy up to at least $500 \mathrm{~Hz}$ (Figure 5), it is expected that the dispersion branches can be measured from the NCF in a larger frequency band, because this processing integrates signal over a much longer duration than the icequakes. For example, Figure 10c shows the dispersion curves obtained from the NCF of the three displacement components. In terms of wavenumber values (or velocities), they are in prefect agreement with those calculated on the same day along line 125 of the main array, using the impulsive sources (Figure 9a). This proves that the velocities of the modes calculated using the NCF are the same as those inferred using the active impulsive sources. An interesting feature is that the dispersion curve of the $Q S$ mode vanishes at frequencies beyond $60 \mathrm{~Hz}$ when using the active sources, but it can be measured on a larger frequency band, up to $150 \mathrm{~Hz}$ when using the NCF. This indicates that the inverse problem may be better constrained with the NCF.

\subsection{Inversion of the Dispersion Curves for Sea Ice Thickness, Young's Modulus, and} Poisson's Ratio

From the approximation of the seismic wavefield in a floating ice layer by Stein et al. (1998), it is straightforward to determine Young's modulus and Poisson's ratio based on the modes velocity:

$$
v=1-2\left(\frac{c_{Q S H_{0}}}{c_{Q S_{0}}}\right)^{2} \text {, and } E=\rho \times\left(c_{Q S_{0}}\right)^{2}\left(1-v^{2}\right) .
$$

However, it should be noted that the use of equation (1) is possible only because the approximation of the $Q S_{0}$ by the axial wave remains valid at our frequencies of interest, that is, between 0 and $150 \mathrm{~Hz}$ (Figure 1b). 
We find values $E=3.9 \pm 0.2 \mathrm{GPa}$ and Poisson's ratio $v=0.34 \pm 0.02$ on 1 March 2019 and $E=4.4 \pm 0.2 \mathrm{GPa}$ and Poisson's ratio $v=0.32 \pm 0.02$ on 5 March 2019 .

To estimate sea ice thickness, the dispersion curve of the $Q S$ mode is used. While the approximation in Stein et al. (1998) holds up to a frequency-thickness of $300 \mathrm{~Hz} \cdot \mathrm{m}$ for the $Q S_{0}$ mode, it holds only up to $50 \mathrm{~Hz} \cdot \mathrm{m}$ for the QS mode (Figure 1b). However, on 1 March 2019, sea ice thickness was greater than $0.5 \mathrm{~m}$. Given that we measure the propagation of the $Q S$ mode up to $150 \mathrm{~Hz}$ (Figure 10c), another model has to be used. For meaningful results we use finite element (FE) modeling instead of the flexural wave approximation.

To this end, we modeled the seismic wavefield propagating in the sagittal plane of an ice layer floating on an infinite water column. FE simulations were made with the commercially available software COMSOL Multiphysics. For water, we used a density $\rho_{w}=1010 \mathrm{~kg} / \mathrm{m}^{3}$ and a speed of sound $c=1410 \mathrm{~m} / \mathrm{s}$. For sea ice, we used a density of $910 \mathrm{~kg} / \mathrm{m}^{3}$ (Timco \& Frederking, 1996), and the elastics constants $E$ and $v$ found previously on each day. Thickness was varied between 0.4 and $0.7 \mathrm{~m}$ with a 1 -cm increment. The seismic source was defined as a vertical force distributed on a $20-\mathrm{cm}$-long zone at the free surface of the ice. We used three different positions of the source, all inline with an array of 44 receivers. They were located 92, 96, and $100 \mathrm{~m}$ away from the first receiver and sent a two-cycle tone burst with central frequency $75 \mathrm{~Hz}$. The processing of the synthetic data was identical with that of the field data. However, because the simulation is two-dimensional, it was applied only to the vertical and longitudinal components of the wavefield.

Note the different relative amplitudes of the modes in the spectra from the synthetic and field data. This is essentially due to the fact that the displacement field used to measure the $Q S_{0}$ mode in the synthetic data was taken at the center of the ice layer, where its energy is strongest. In the field data, we have only access to data measured at the surface of the ice, where the $Q S$ mode is dominant. In the spectra calculated from the icequakes, however, the difference in relative amplitude is not so significant. This is because the source mechanism is not the same when jumping on the ice or when cracking occurs. The former generates essentially a vertical motion, and thus, energy goes mainly to the $Q S$ mode, while the latter generates motion in the whole thickness and energy is distributed more evenly between the modes.

The dispersion curves calculated on 1 March 2019 from the impulsive sources or the NCF are in very good agreement with those for a simulated ice layer of thickness $h=54 \pm 3 \mathrm{~cm}$, Young's Modulus $E=3.9 \mathrm{GPa}$, and Poisson's ratio $v=0.34$ (Figure 9c). The dispersion curves calculated on 5 March 2019 from the icequakes correspond to a simulated ice layer of thickness $h=58 \pm 3 \mathrm{~cm}$, Young's Modulus $E=4.4 \mathrm{GPa}$, and Poisson's ratio $v=0.32$ (Figure 9c).

These parameters are consistent with field observations and with values generally found in literature for sea ice:

- Thickness estimation on 1 March 2019 is consistent with that from the GPR acquisition along the east-west direction on the same day $(52 \mathrm{~cm})$. Drilling through the ice on 1 March 2019 revealed a slightly larger thickness of $62 \mathrm{~cm}$. However, this does not mean that our thickness estimation from the dispersion curves is wrong, for two reasons. First, drilling was performed $20 \mathrm{~m}$ to the south of line 125 (see exact position in Figure $3 b$ ), and the spatial variability of the ice thickness was most likely around 15-20\%. Second, as explained in section 3.4.2, the dispersion curves correspond to an average velocity along the propagation of the wavefield; hence, our thickness estimations correspond to an average value along the stations of line 125.

- Poisson's ratio is typical for sea ice (Mellor, 1986; Schulson \& Duval, 2009).

- Young's moduli are consistent with values reported in Hunkins (1960) and Anderson (1958) for first-year ice, which is more porous and with a large brine content.

\subsection{Discussion}

The value of Young's modulus for sea ice is about half that of fresh-water ice (Gammon et al., 1983). However, in the Van Mijen fjord, the salinity in March is generally around 6\%o (Hoyland, 2009) and the brine-liquid volume was shown to vary between 95\%o in 2010 and 30\% in 2018 (Karulin et al., 2019). At Vallunden Lake, the ice contained much brine and was quite porous, with water drawn to the surface from capillarity effect. Young's modulus is known to decrease when porosity and brine content increase (Langleben \& Pounder, 1963; Mellor, 1986). The ice was also very brittle in the top $30 \mathrm{~cm}$. Moreover, the ice in the field had a temperature of about $-1{ }^{\circ} \mathrm{C}$ in the bottom $10 \mathrm{~cm}$. For ice temperatures above $-3{ }^{\circ} \mathrm{C}$, Young's modulus 
is significantly reduced (Hunkins, 1960). These observation simply a gradient of mechanical properties through the ice layer. The snow layer covering the ice surface may also have an influence on the apparent Young's modulus (Schulson \& Duval, 2009). Our onsite radar acquisitions show that the thickness of the snow was between 20 and $35 \mathrm{~cm}$ along row 125 (Figure $4 \mathrm{~b}$ ).

The combined effects of ice porosity, brine, and the snow cover affect the speed of the guided modes, which propagate with a reduced velocity in comparison with fresh-water ice. For example, the dispersion curves measured in Moreau, Lachaud et al. (2017) for a floating layer of pure ice with thickness of $1 \mathrm{~cm}$, Young's modulus $E=9.4 \mathrm{GPa}$, and Poisson's ratio $v=0.33$ indicated a velocity of $3,215 \mathrm{~m} / \mathrm{s}$ for the $Q S_{0}$ mode. The velocity of the $Q S$ mode was $430 \mathrm{~m} / \mathrm{s}$ for a frequency of 3,700 Hz that is for a frequency-thickness of $37 \mathrm{~Hz} \cdot \mathrm{m}$. In sea ice at Vallunden Lake, for the same frequency-thickness (i.e., at a frequency of $60 \mathrm{~Hz}$ and thickness of $62 \mathrm{~cm}$ ), the $Q S$ mode propagates with a reduced velocity of $287 \mathrm{~m} / \mathrm{s}$. This indicates that the effective elastic properties estimated in sea ice with seismic methods are necessarily less than those of fresh-water ice measured at the ultrasonic scale, where mesoscale heterogeneities have no influence.

The differences between the elastic properties estimated on 1 and 5 March 2019 remain within the error bars. This is expected, since the ice should not undergo significant changes of properties within only 4 days. The estimations of the ice thickness remains within the error bars too, but we believe that the 4-cm increase in thickness is not related to uncertainties. Between 1 and 26 March 2019, drillings indicate a thickness increase of about $20 \mathrm{~cm}$, which is not surprising given the cold weather conditions in the field, with an average temperature of about $-25^{\circ} \mathrm{C}$.

Overall, the use of passive seismic data seems very promising for monitoring the thickness and mechanical properties of sea ice. However, the monitoring over the 27-day period is left for future works, since investigating NCF requires significant additional analyses that are beyond the scope of this paper. Future works will also investigate inversions based on a forward model that accounts for ice porosity, gradient of mechanical properties, and a snow layer. This should pave the way toward more systematic applications of passive methods for monitoring sea ice. The interest lies not only in the context of climate change at the global scale but also at a more local scale for monitoring the ice condition in places where fast ice is used for traveling.

\section{Concluding Remarks}

This paper presented a proof of concept to use passive seismic data for estimating sea ice thickness and properties. We show preliminary results from seismic data acquired on sea ice with an array of geophones deployed in the Van Mijen fjord near Sveagruva (Svalbard). The array recorded continuously the ambient seismic field for 27 consecutive days between 28 February and 26 March 2019, resulting in a sea ice seismic data set of unprecedented quality, both in terms of spatial and temporal sampling and also in terms of the acquisition duration. Based on passive acquisitions and appropriate signal processing, we show that broadband propagation of the seismic waves guided in sea ice can be extracted with the same level of accuracy compared to data from active seismic experiments. The dispersion curves of three fundamental guided modes are measured either with an active source or with passive seismic data, in the 1-150 $\mathrm{Hz}$ frequency range. The dispersion curves obtained on 1 March 2019 with active sources or the NCF show very good agreement with synthetic data in a layer of floating ice with thickness $h=0.54 \mathrm{~m}$, Young's modulus $E=3.9 \mathrm{GPa}$, and Poisson's ratio $v=0.34$. Those obtained on 5 March 2019 from icequakes show very good agreement with synthetic data in layer of floating ice with a thickness of $h=0.58 \mathrm{~m}$, Youngs modulus $E=4.4 \mathrm{GPa}$, and Poisson's ratio $v=0.32$. These values are consistent with field observations and reports in the literature. A major perspective of this work is the monitoring of these parameters for the whole duration of the experiment, for example, by producing a daily three-dimensional map of the ice properties. To this end, instead of using just one linear array, the four linear arrays will be used as virtual sources to calculate the NCF and recover wave propagation in all directions.

We are confident that the approach introduced in this paper can be complementary to the already existing methods for monitoring sea ice properties. Applications are for both landfast ice and ice floes. The origin of mechanical stress in ice floes is mainly due to interior deformation resulting from relative drift and thermal expansion of the ice, while at Vallunden Lake it is dominated by tidal forcing. Hence, there might not be as many icequakes in ice floes as those recorded in this experiment, but not as many are necessary. Moreover, 
reverberation in ice floes may play a important role in this matter, since each reflection at the edge acts as a secondary noise source, which is desirable for the convergence of the NCF.

Key aspects for a transfer of this concept to systematic monitoring of sea ice with the ambient seismic wavefield are battery life and the determination of optimal array size and density for best spatial coverage and accuracy. The former is a technological issue. The geophones used in this experiment allow continuous recordings for 40 days at a sampling rate of $500 \mathrm{~Hz}$. The next generation of geophones will be able to record continuously for several months and transmit data via a $4 \mathrm{G}$ connection. Moreover, continuous recording of the wavefield is not necessary to extract the dispersion curves from the NCF, because it converges after only a few hours of ambient field records are processed. The latter will be tackled by studying the sensitivity of the inverse problem to measurement errors, which are directly linked to spatial sampling and frequency bandwidth.

Measuring broadband propagation of the three guided modes from passive seismic data is an important step toward the assessment of a more optimal array design in terms of spatial sampling. For example, a linear array of 30 geophones with 10- to 15-m spacing might allow the extraction of the dispersion curves of the three modes on a bandwidth that is sufficient for estimating sea ice properties. This remains to be confirmed with future investigations, by focusing on a systematic search of suitable icequakes and the calculation of the NCF, as these may play a complementary role to achieve this goal.

\section{Appendix A: Positions and Date of the Vibrating and Impulsive Sources (Times are UTC)}

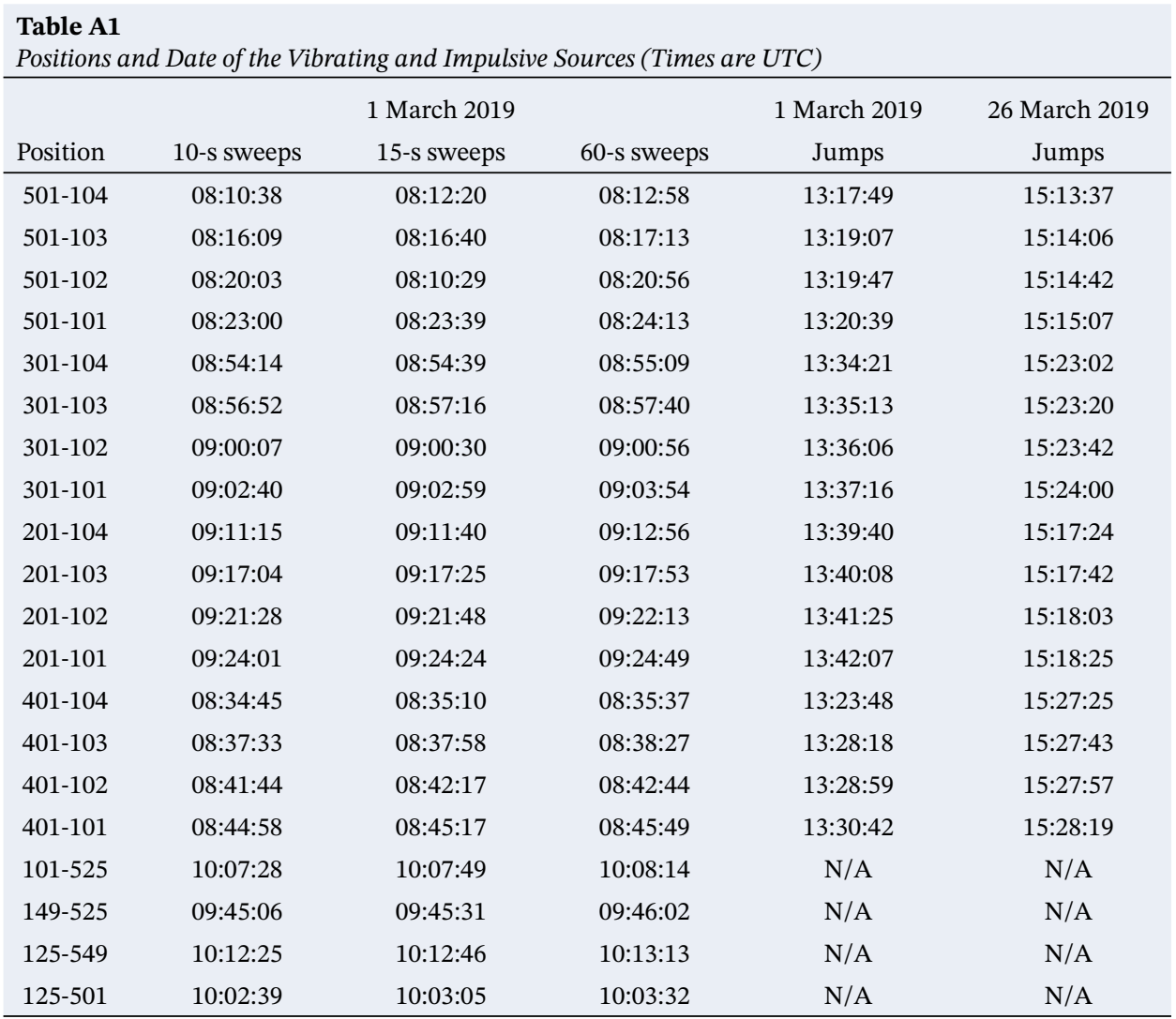

\section{Appendix B: Dispersion Curves Obtained From the Classical Spatio-Temporal Fourier Transform}


(a)

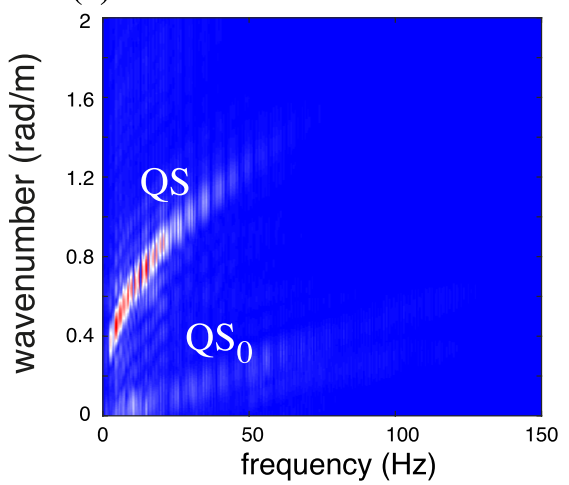

(b)

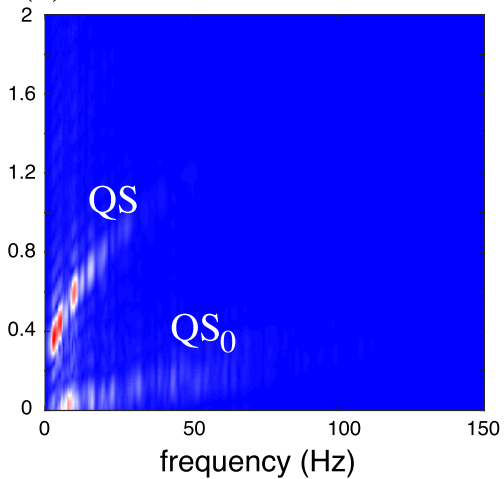

Figure B1. (a, b) Same as Figures 9a and 9b but calculated with classical frequency-wave number Fourier transforms.

\section{Appendix C: Velocities Extracted From the Dispersion Curves Calculated in Section 3.4.2}

(a)

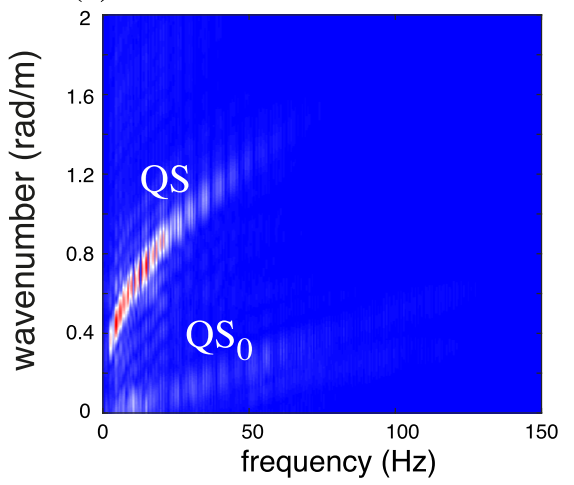

(b)

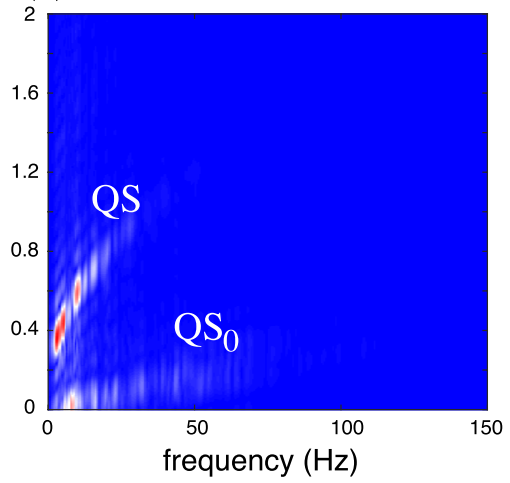

Acknowledgments

All metadata of this experiment are available online (https://doi.org/10. 15778/RESIF.XG2019). The full data set (total size $=3.2 \mathrm{To}$ ) is available upon request to the corresponding author. A subset can be accessed instantly via a direct download link. To request this link, please send an e-mail (resif-dc@ujf-grenoble.fr)with your affiliation and IP address. This subset contains the continuous recordings of all stations on 1, 3, and 5 March 2019, from which the results presented in this paper were obtained (with $3 \mathrm{C}$ stations data downsampled at $500 \mathrm{~Hz}$ ). ISTerre is part of Labex OSUG@2020. This research was funded by the Agence Nationale de la Recherche (ANR, France) and by the Institut Polaire Français Paul-Emile Victor (IPEV). Most of the computations presented here were performed using the CIMENT infrastructure (https:// ciment.ujf-grenoble.fr), which is supported by the Rhone-Alpes region (Grant CPER07_13 CIRA: http://www. ci-ra.org) and France-Grille (http:// www.france-grilles.fr). We thank Pr. Aleksey Marchenko from the University Centre in Svalbard for the valuable advices and discussions. G. Hillers acknowledges support funding from the University of Helsinki Faculty of Science. All authors also want to thank the reviewers, the Editor, Dr. L. Padman, and Dr. G. Taylor for their comments that helped to improve the manuscript.
Figure C1. (a, b) Same as Figures 9a and 9b but calculated with classical frequency-wave number Fourier transforms.

\section{References}

Anderson, D. L. (1958). Preliminary results and review of sea ice elasticity and related studies. Transactions of the Engineering Institute of Canada, 2, 116-122.

Chylek, P., Folland, C. K., Lesins, G., Dubey, M. K., \& Wang, M. Y. (2009). Arctic air temperature change amplification and the Atlantic Multidecadal Oscillation. Geophysical Research Letters, 36, L14801. https://doi.org/10.1029/2009GL038777

Gammon, P. H., Kiefte, H., Clouter, M. J., \& Denner, W. W. (1983). Elastic constants of artificial and natural ice samples by Brillouin spectroscopy. Journal of Glaciology, 29(103), 433-460. https://doi.org/10.3189/S0022143000030355

Gimbert, F., Jourdain, N. C., Marsan, D., Weiss, J., \& Barnier, B. (2012). Recent mechanical weakening of the Arctic sea ice cover as revealed from larger inertial oscillations. Journal of Geophysical Research, 299, C00J12 - elocator. https://doi.org/10.1029/2011JC007633

Hoyland, K. V. (2009). Ice thickness, growth and salinity in Van Mijenfjorden Svalbard, Norway. Polar Research, 28(3), 339-352. https:// doi.org/10.1111/j.1751-8369.2009.00133.x

Hunkins, K. (1960). Seismic studies of sea ice. Journal of Geophysical Research, 65(10), 3459-3472. https://doi.org/10.1029/ JZ065i010p03459

IPCC (2014). Climate change synthesis report. In Contribution of Working Groups I, II and III to the Fifth Assessment Report of the Intergovernmental Panel on Climate Change Rep. 151. Geneva, Switzerland: IPCC.

Kanao, M., Zhao, D., Wiens, D. A., \& Stutzmann, E. (2015). Recent advance in polar seismology: Global impact of the International Polar Year. Polar Science, 9(1), 1-4. https://doi.org/10.1016/j.polar.2014.12.003

Karulin, E. B., Marchenko, A. V., Sakharov, A. N., Karulina, M. M., Chistyakov, P. V., \& Onishchenko, D. A. (2019). Features of determining the ice flexural strength and the elastic modulus based on floating cantilever beam tests. In Proceedings of the 25th International Conference on Port and Ocean Engineering under Arctic Conditions, June, 2019. Delft.

Lamb, H. (1917). On waves in an elastic plate. Proceedings of the Royal Society A., 93(648), 114-128. https://doi.org/10.1098/rspa.1917.0008 Langleben, M. P., \& Pounder, E. R. (1963). Elastic parameters of sea ice, Ice and snow; properties, processes, and applications: proceedings of a conference held at the Massachusetts Institute of Technology, February 12-16, 1962 (pp. 69-78). Cambridge: Mass, M.I.T. Press.

Liu, H., Takahashi, K., \& Sato, M. (2014). Measurement of dielectric permittivity and thickness of snow and ice on a brackish lagoon using GPR. IEEE Journal of Selected Topics in Applied Earth Observations and Remote Sensing, 7(3), 820-827. https://doi.org/10.1109/JSTARS. 2013.2266792

Marsan, D., Weiss, J., Larose, E., \& Métaxian, J.-P. (2012). Sea-ice thickness measurement based on the dispersion of ice swell. Journal of the Acoustical Society of America, 131(1), 80-91. https://doi.org/10.1121/1.3662051 
Marsan, D., Weiss, J., Moreau, L., Gimbert, F., Doble, M., Larose, E., \& Grangeon, J. (2019). Characterizing horizontally-polarized shear and infragravity vibrational modes in the Arctic sea ice cover using correlation methods. Journal of the Acoustical Society of America, 145(3), 1600-1608. https://doi.org/10.1121/1.5094343

Mellor, M. (1986). Mechanical behavior of sea ice. In N. Untersteiner (Ed.), The Geophysics of Sea Ice, NATO ASI Series (Series B: Physics). Boston, MA: Springer.

Miller, B. E., \& Schmidt, H. (1991). Observation and inversion of seismo-acoustic waves in a complex arctic ice environment. Journal of the Acoustical Society of America, 89(4), 1668-1685. https://doi.org/10.1121/1.401000

Minonzio, J.-G., Talmant, M., \& Laugier, P. (2010). Guided wave phase velocity measurement using multi-emitter and multi-receiver arrays in the axial transmission configuration. Journal of the Acoustical Society of America, 127(5), 2913-2919. https://doi.org/10.1121/ 1.3377085

Moreau, L., Lachaud, C., Thry, R., Predoi, M. V., Marsan, D., Weiss, J., \& Montagnat, M. (2017). Monitoring ice thickness and elastic properties from the measurement of leaky guided waves: A laboratory experiment. Journal of the Acoustical Society of America, 142(5), 2873-2880. https://doi.org/10.1121/1.5009933

Moreau, L., Minonzio, J.-G., Talmant, M., \& Laugier, P. (2014). Measuring the wavenumber of guided modes in waveguides with linearly varying thickness. Journal of the Acoustical Society of America, 135(5), 2614-2624. https://doi.org/10.1121/1.4869691

Moreau, L., Stehly, L., Boué, P., Lu, Y., Larose, E., \& Campillo, M. (2017). Improving ambient noise correlation functions with an svd-based Wiener filter. Geophysical Journal International, 211(1), 418-426. https://doi.org/10.1093/gji/ggx306

Pounder, E. R., \& Langleben, M. P. (1964). Artctic sea ice of various ages 2. Elastic Properties. Journal of Glaciology, 5(37), 99-105. https:// doi.org/10.3189/S0022143000028616

Rampal, P., Weiss, J., Dubois, C., \& Campin, J. M. (2011). IPCC climate models do not capture Arctic sea ice drift acceleration: Consequences in terms of projected sea ice thinning and decline. Journal of Geophysical Research, 116, C00D07. https://doi.org/10.1029/2011JC007110

Rampal, P., Weiss, J., Marsan, D., \& Bourgoin, M. (2009). Arctic sea ice velocity field: General circulation and turbulent-like fluctuations Journal of Geophysical Research, 114, C10014. https://doi.org/10.1029/2008JC005227

Rost, T., \& Thomas, C. (2002). Array seismology: Methods and applications. Reviews of Geophysics, 40(3), 1008. https://doi.org/10.1029/ 2000RG000100

Sabra, K. G., Gerstoft, P., Roux, P., Kuperman, W. A., \& Fehler, M. C. (2005). Extracting time-domain Green's function estimates from ambient seismic noise. Geophysical Research Letters, 32, L03310 - elocator. https://doi.org/10.1029/2004GL021862

Schulson, E., \& Duval, P. (2009). Creep and fracture of ice. Cambridge: Cambridge University Press. https://doi.org/10.1017/ CBO9780511581397

Shapiro, N. M., \& Campillo, M. (2004). Emergence of broadband Rayleigh waves from correlations of the ambient seismic noise. Geophysical Research Letters, 31, L07614. https://doi.org/10.1029/2004GL019491

Steffen, W., Rockstrm, J., Richardson, K., Lenton, T. M., Folke, C., Liverman, D., et al. (2018). Trajectories of the Earth System in the Anthropocene. Proceedings of the National Academy of Sciences, 155(33), 21,783-21,796.

Stein, P. J., Euerle, S. E., \& Parinella, J. C. (1998). Inversion of pack ice elastic wave data to obtain ice physical properties. Journal of Geophysical Research, 103(C10), 21,783-21,796.

Stroeve, J., Holland, M. M., Meier, W., Scambos, T., \& Serreze, M. (2007). Arctic sea ice decline: Faster than forecast. Geophysical Research Letters, 34, L09501. https://doi.org/10.1029/2007GL029703

Stroeve, J. C., Kattsov, V., Barrett, A., Serreze, M., Pavlova, T., Holland, M., \& Meier, W. N. (2012). Trends in Arctic sea ice extent from CMIP5, CMIP3 and observations. Geophysical Research Letters, 39, L16502. https://doi.org/10.1029/2012GL052676

Sutherland, G., \& Rabault, J. (2016). Observations of wave dispersion and attenuation in landfast ice. Journal of Geophysical Research: Oceans, 121, 1984-1997. https://doi.org/10.1002/2015JC011446

Timco, G. W., \& Frederking, R. M. W. (1996). A review of sea ice density. Cold Regions Science and Technology, 24(1), 1-6.

Uttal, T., Curry, J. A., McPhee, M. G., Perovich, D. K., Moritz, R. E., Maslanik, J. A., et al. (2002). Surface heat budget of the Arctic Ocean. Bulletin of the American Meteorological Society, 83(2), 255-276. https://doi.org/10.1175/1520-0477(2002)083<0255:SHBOTA>2.3.CO;2

Weeks, W. F., \& Ackley, S. F. (1986). The growth, structure and properties of sea ice. In N. Untersteiner (Ed.), The Geophysics of Sea Ice, NATO ASI Series (Series B: Physics). Boston, MA: Springer.

Yang, T. C., \& Giellis, G. R. (1994). Experimental characterization of elastic waves in a floating ice sheet. Bulletin of the American Meteorological Society, 83(2), 255-276. 